\title{
Antidepressant-like effect of ethanolic extract from Caryophyllus aromaticus in albino rats
}

\author{
${ }^{1}$ Sangavai Mathiazhagan, ${ }^{2}$ S. Anand, R.Parthiban, ${ }^{3}$ B. Sankaranarayanan, \\ ${ }^{4}$ S. Suresh \\ ${ }^{1,2,34}$ Department of Pharmacology, Sree Balaji Medical College And Hospital, Chromepet, Chennai.
}

\begin{abstract}
Objective: Caryophyllus aromaticus mill L (Caryophyllus aromaticus) is a herbal spice plant that has several therapeutic effects. It also heals depression, grief, nervous stress and tension. In the present study we evaluated antidepressant-like effect of Caryophyllus aromaticus using forced swimming test (FST).

Material and Methods: Three doses of ethanolic extract (50, 100 and $200 \mathrm{mg} / \mathrm{kg}$ ) was injected intraperitoneally. After 30 min of injection, immobility and swimming times were measured and compared with control (negative control) and imipramine (positive control).

Results: The results showed that higher dose $(200 \mathrm{mg} / \mathrm{kg})$ of extract significantly increased swimming time and decreased immobility time. However, the two lower doses of extract (50 and 100mg/kg) also had significant effect on these parameters.
\end{abstract}

Conclusion: These results proposed antidepressant-like effect of higher dose concentration of ethanolic extract of Caryophyllus aromaticus

Keywords: Caryophyllus aromaticus, Rats, Immobility time, Antidepressant-like effect

\section{Introduction}

According to the World Health report [1], approximately 450 million people suffer from a mental or behavioral disorder, yet only a small minority of them receives even the most basic treatment. This amounts to $12.3 \%$ of the global burden of disease, and will rise to $15 \%$ by 2020 [2]. Depression is the most prevalent mental disorder and depression is recognized to be symptomatically, psychologically and biologically heterogeneous [3]. Antidepressant drugs such as tricyclic antidepressants, and selective serotonin reuptake inhibitors (SSRI) are used to treat depression showing various side effect and thus, the search for a new antidepressant herb without side effects is deemed important [4].

Various plants are being used in complementary and alternative medicines for management of depression. Caryophyllus aromaticus species have been particularly attributed with mood enhancing properties by aroma therapists. Volatile oils isolated from whole plant Caryophyllus aromaticus are often used in the treatment of anxiety and depression. A review of literature revealed that Caryophyllus aromaticus is highly reputed plant, and has been widely employed in herbal medicine and aromatherapy [5] but no significant work has been carried out on the anti-depressant activity of the plant extracts. So, the present study was designed to evaluate the anti Depressant activity of ethanol extract of Caryophyllus aromaticus.

\section{Plant Material:}

\section{Materials And Methods}

Clove buds (Caryophyllus aromaticus) was Purchased from the local market in Chennai and identified by The Director, National institute of herbal science, west tambaram, Chennai.

\section{Experimental animals}

Albino rats of Wistar strain of either sex weighing 200gm were used for the study. Animals were purchased from King Institute of Preventive Medicine, Guindy, Chennai and maintained in the Central Animal House, Sree Balaji Medical College and Hospital, Chennai, India. The animals were individually housed under controlled temperature and hygienic conditions. They all 
received a standard pellet diet and water ad libitum. Institutional Animal Ethics Committee approved the experimental protocol.

\section{Preparation Of Caryophyllus aromaticus Extract}

Clove buds were obtained from the local market was shade dried and powdered using mechanical mixer. The plant extract Caryophyllus aromaticus was prepared using soxhlet apparatus, by maceration of $50 \mathrm{~g}$ of the chopped, dried buds of in a mixture of $200 \mathrm{ml}$ ethanol and $200 \mathrm{ml}$ distilled water by shaking them for $48 \mathrm{~h}$ and pressing the solution out of the material using a filter press. The extraction solvent was then removed under reduced pressure until the extract was obtained as a dried gum. The final extracted material weighed $10 \mathrm{~g}$. Concentrations of the extract were prepared by dissolving final product in distilled water.

All the other chemicals like imipramine were of analytical grade and were procured from local commercial companies.

\section{Experimental groups}

In this experiment the following groups ( $\mathrm{n}=6$ for each group) were used:

1- Saline as the negative control

2-Imipramine $(30 \mathrm{mg} / \mathrm{kg})$ as positive control

3- Ethanolic extract group $(50 \mathrm{mg} / \mathrm{kg})$

4- Ethanolic extract group $(100 \mathrm{mg} / \mathrm{kg})$

5 - Ethanolic extract group $(200 \mathrm{mg} / \mathrm{kg})$

\section{Screening Method For Antidepressant Activity Forced Swimming Test}

The forced swimming test was used for the evaluation of antidepressant effect of Caryophyllus aromaticus in rats. Animals were placed in pyrex cylinders $(10 \times 45 \mathrm{~cm})$ which were filled with water at $24-25^{\circ} \mathrm{C}$ with a $30-\mathrm{cm}$ depth and behaviors were monitored. Saline, imipramine and ethanolic extract Caryophyllus aromaticus of were administered intraperitoneally $30 \mathrm{~min}$ prior to the test session. The duration of test was 6 min. After two min, immobility and swimming time was measured during the last $4 \mathrm{~min}$ [6]. Immobility was assigned when no additional activity was observed other than that required to keep the animal's head above the water and swimming time assigned when animal did active movement of extremities and circling in the container.

\section{Statistical analysis}

concentrations of extract was made using ANOVA test. Significance was accepted at $\mathrm{p}<0.001$.

\section{Results}

\section{The effect of imipramine on immobility and swimming times in rat using forced swim test}

The effect of imipramine $(30 \mathrm{mg} / \mathrm{kg})$ on immobility and swimming time in FST in rats has been shown in Figures 1, 2. As shown, injection of imipramine significantly decreased immobility $(24.83 \pm 0.167 \mathrm{sec} v s 83 \pm 0.10 \mathrm{sec}, \mathrm{p}<0.001)$ and increased swimming $(220.17 \pm 0.167 \mathrm{sec} v s 151 \pm 0.10$ $\mathrm{sec}, \mathrm{p}<0.001)$ times compared to the control group.

\section{The effect of ethanolic extracts of Caryophyllus aromaticus on immobility and swimming times in rat using forced swim test}

Three different doses of ethanolic extract $(50,100$ and $200 \mathrm{mg} / \mathrm{kg}$ ) of Caryophyllus aromaticus showed different effects on FST. Ethanolic extracts at the dose of $50 \mathrm{mg} / \mathrm{kg}$ significantly decreased immobility $(44.83 \pm 0.401 \mathrm{sec} v s 83 \mathrm{sec} \mathrm{p}<0.001)$ and increased swimming $(171.50 \pm$ 0.342sec vs $151 \mathrm{sec}, \mathrm{p}<0.001)$ time in rats compared to the control group. However, these effects didn't reach the statistically significant level compared to imipramine. The dose of $100 \mathrm{mg} / \mathrm{kg}$ of this extract had statistically significant effect on immobility $(32.17 \pm 0.401 \mathrm{sec} v \mathrm{~s}$

$83 \mathrm{sec}, \mathrm{p}<0.001)$ and swimming $(192.67 \pm 0.211 \mathrm{sec} v s 151 \mathrm{sec}, \mathrm{p}<0.001)$ times compared to the saline group. The dose of $200 \mathrm{mg} / \mathrm{kg}$ of this extract significantly decreased immobility time $(24.33 \pm 0.211$ 
sec vs $83 \mathrm{sec}, \mathrm{p}<0.001)$ and increased swimming time $(221.83 \pm 0.543 \mathrm{sec}$ vs $151 \mathrm{sec}, \mathrm{p}<0.001)$ compared to the saline group. Immobility and swimming times in this dose also significantly decreased and increased respectively compared to imipramine $(p<0.001)$. In addition, there was significant difference in immobility and swimming times between low and high doses of the extract $(\mathrm{p}<0.001)$. Hence, from the above results it can be seen that among the three doses of the extract used, the most effective dose for antidepressant action using forced swim test is $200 \mathrm{mg} / \mathrm{kg}$ of Caryophyllus aromaticus .

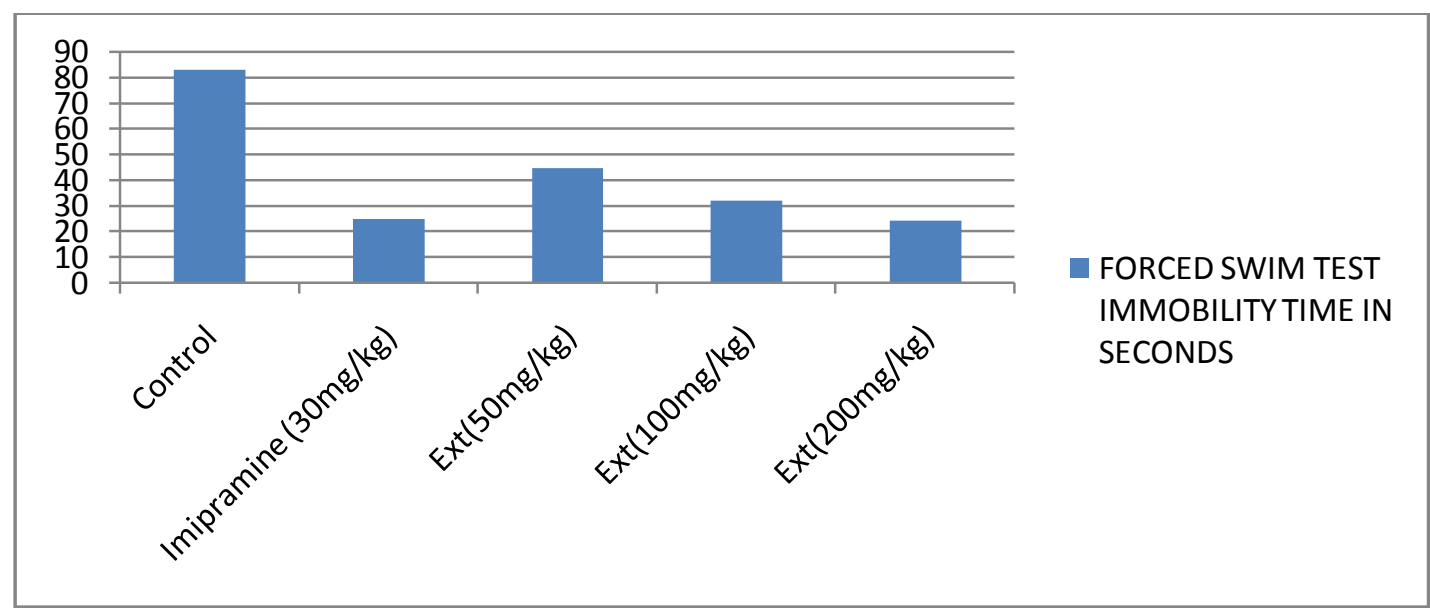

Figure 1 Effects of ethanolic extract of Caryophyllus aromaticus on immobility time in rats. Data are expressed as means \pm SEM $(n=6)$.

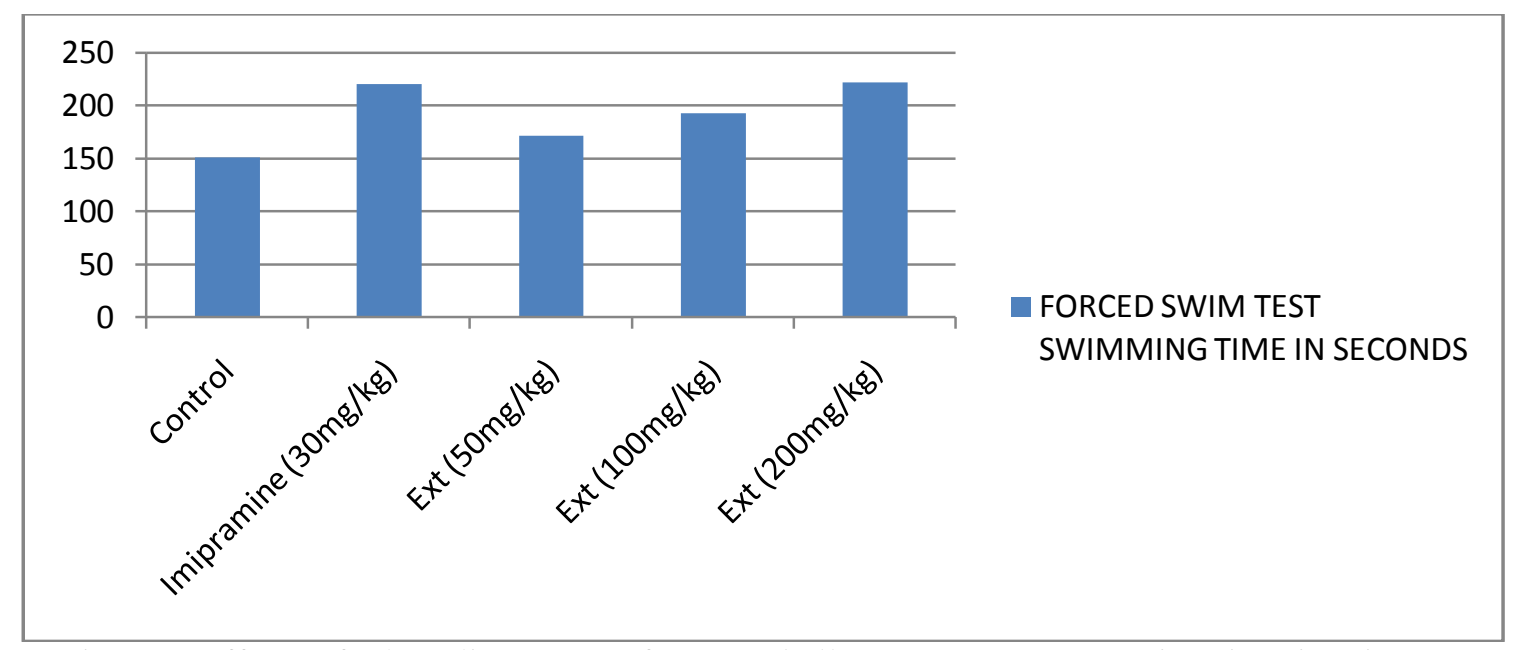

Figure 2 Effects of ethanolic extract of Caryophyllus aromaticus on swimming time in rats. Data are expressed as means \pm SEM $(n=6)$.

\section{Discussion}

The present study was conducted to study the antidepressant effect of Caryophyllus aromaticus on albino rats. To see the effectiveness of Caryophyllus aromaticus it is compared with a standard drug imipramine.

Caryophyllus aromaticus is found abundantly in India and also in tropical and sub-tropical countries throughout the world. Every part of the plant has some medicinal properties that has been used traditionally since ancient times.

Despite the widespread uses of the plant, no scientific work is reported in literature regarding the effect of Caryophyllus aromaticus (clove buds) against depression like states, therefore, present study was undertaken to evaluate antidepressant effects of ethanolic extract of Caryophyllus aromaticus (clove buds)using forced swim test in rats. Studies were also conducted to find its interaction with conventional antidepressant drug in order to elucidate its probable mode of action. 
In this study, antidepressant effect of Caryophyllus aromaticus has been studied. For this purpose, forced swimming test was used. In forced swim test, the duration of immobility time and swimming time of the three doses of ethanolic extract from Caryophyllus aromaticus in comparison with saline (negative control) and imipramine (positive control) were evaluated. The symbol of depression is immobility and forced swimming test is a well known animal model for evaluating depression. In FST, rats forced to swim in a restricted space quickly abandon swimming and stand still. This behavior is named immobility and shows lowered mood. The agents that reduce this despair behavior are known as antidepressant drugs [7]. In a new method of FST, in addition to immobility time, swimming time is also measured. Based on this method, drugs that inhibit norepinephrine reuptake, decrease immobility time without any significant effect on swimming time. Drugs that selectively inhibit serotonin reuptake decrease immobility and increase swimming time [8]. One of the important neurotransmitters involved in the depression are monoamines. It is well-known that low level of monoamines in synapses causes depression and classical antidepressants such as imipramine by inhibiting reuptake of monoamines (5-HT and noradrenalin) increase levels of these neurotransmitters and show antidepressant activity [9,10,11]. In this study, the higher dose of ethanolic extract of Caryophyllus aromaticus caused a significant reduction in immobility time and increased swimming time. The effect of this dose of extract was comparable to imipramine. Therefore we suggest that antidepressant-like effect of ethanolic extract of Caryophyllus aromaticus maybe mediated by reuptake inhibition of monoamine neurotransmitters (the same mechanism as imipramine). In addition, because low concentration of the extract significantly decreased immobility time and increased swimming time, therefore this dose may has serotonin reuptake inhibitory effect. Caryophyllus aromaticus contains several components such as flavonoids, kaempferol, rhamnetin, eugenol, sterols that have several pharmacological activities in the CNS. The role of these compounds for antidepressant effect of Caryophyllus aromaticus is not defined. However, it has been reported that plants containing compounds such as flavonoids, and kaempefrol show antidepressant effect [12,13]. It has also been shown that kaempefrol has antidepressant effect [6]. In addition, it has been reported that flavonoids and kaempefrol show inhibitory effect on mono-amino oxidase enzyme (MAO) in vitro [13,14].Therefore, it can be suggested that flavonoids and kaempefrol of Caryophyllus aromaticus are important compounds which may be responsible for its antidepressant effect.

This therapeutic potential should be further investigated by a dose response experiment and by isolating and identifying the substances responsible for the release of anti-depressant products, followed by studies based on the use of pure substances in suitable formulations.

\section{References}

[1] The World Health Report. Mental health: new understanding new hope. WHO, Geneva, 2001

[2] Reynolds EH. Brain and mind: a challenge for WHO. Lancet 2003; 361:1924-1925.

[3] Soulimani R, Younos C, Jarmouni S, Bousta D, Misslin R and Mortier F. Behavioral effects of Passiflora incarnata L. and its indole alkaloid and flavonoid derivatives and maltol in the mouse. J. Ethnopharmacol 1997; 57: 11-20.

[4] Chambers CD, Hernandez-Diaz S, Van Marter L J, Werler M M, Louik C, Jones K L, Mitchell AA. Selective serotonin-reuptake inhibitors and risk of persistent pulmonary hypertension of the newborn. .N. Engl. J. Med 2006, 354:579—587.

[5] David Schiller, 2008.The Aromatherapy Encyclopedia: A concise guide to 385 Essential Plant Oils

[6] Hosseinzadeh H, Motamedshariaty V, Hadizadeh F. 2007. Antidepressant effect of kaempferol, a constituent of saffron (Crocus sativus) petal, in mice and rats. Pharmacologyonline, 2: 367-370.

[7] Porsolt RD, Bertin A, Blavet N, Deniel M, Jalfre M. 1979 . Immobility induced by forced swimming in rats: Effects of agents which modify central catecholamine and serotonin activity. European Journal of Pharmacology, 57(2-3): 201-210.

[8] Detke MJ, Johnson J, Lucki I. 1997. Acute and chronic antidepressant drug treatment in the rat forced swimming test model of depression. Experimental and clinical psychopharmacology, 5(2):107.

[9] Katzong Bertram G. 2001. Basic and clinical pharmacology, New York: McGraw-Hill.

[10] Sanchez-Mateo C, Bonkanka C, Prado B, Rabanal R. 2007. Antidepressant activity of some Hypericum reflexum L. fil. extracts in the forced swimming test in mice. Journal of ethnopharmacology, 112(1): 115-121

[11] Rojas P, Serrano-García N, Medina-Campos ON, Pedraza-Chaverri J, et al .2011. Antidepressant-like effect of a Ginkgo biloba extract (EGb761) in the mouse forced swimming test: Role of oxidative stress. Neurochemistry International.(in press)

[12] Velioglu Y, Mazza G .1991. Characterization of flavonoids in petals of Rosa damascene by HPLC and spectral analysis. Journal of agricultural and food chemistry, 39(3): 463-467.

[13] Moallem SA, Hosseinzadeh H, Ghoncheh H. 2007. Evaluation of Antidepressant Effects of Aerial Parts of Echium vulgare on Mice. Iranian Journal of Basic Medical Sciences, 10: 189 - 196

[14] Butterweck V, Nahrstedt A, Evans J, Hufeisen S, Rauser L, Savage J, et al. 2002. In vitro receptor screening of pure constituents of St. John's wort reveals novel interactions with a number of GPCRs. Psychopharmacologia, 162(2):193-202 